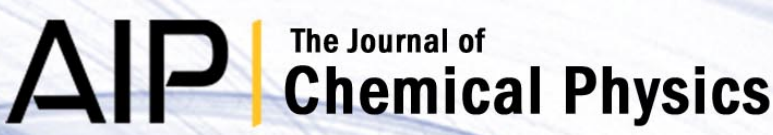

\section{Molecular structure of uranium carbides: Isomers of UC3}

M. Fernanda Zalazar, Víctor M. Rayón, and Antonio Largo

Citation: J. Chem. Phys. 138, 114307 (2013); doi: 10.1063/1.4795237

View online: http://dx.doi.org/10.1063/1.4795237

View Table of Contents: http://jcp.aip.org/resource/1/JCPSA6/v138/i11

Published by the American Institute of Physics.

\section{Additional information on J. Chem. Phys.}

Journal Homepage: http://jcp.aip.org/

Journal Information: http://jcp.aip.org/about/about_the_journal

Top downloads: http://jcp.aip.org/features/most_downloaded

Information for Authors: http://jcp.aip.org/authors

\section{ADVERTISEMENT}

\section{Instruments for advanced science}
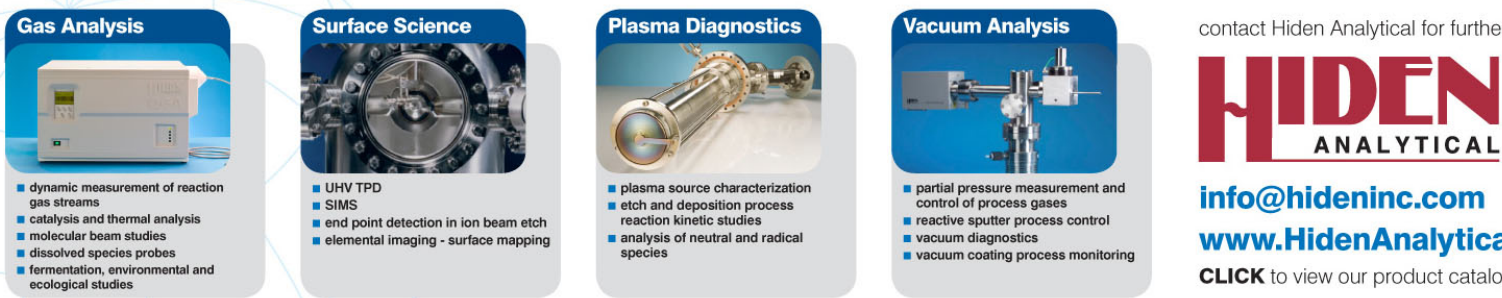

info@hideninc.com www.HidenAnalytical.com CLICK to view our product catalogue 


\title{
Molecular structure of uranium carbides: Isomers of $\mathrm{UC}_{3}$
}

\author{
M. Fernanda Zalazar, ${ }^{1}$ Víctor M. Rayón, ${ }^{2}$ and Antonio Largo ${ }^{2, a)}$ \\ ${ }^{1}$ Laboratorio de Estructura Molecular y Propiedades, Área de Química Física, Departamento de Química, \\ Facultad de Ciencias Exactas y Naturales y Agrimensura, Universidad Nacional del Nordeste, \\ Avenida Libertad 5460, (3400) Corrientes, Argentina \\ ${ }^{2}$ Departamento de Química Física y Química Inorgánica, Facultad de Ciencias, Universidad de Valladolid, \\ Campus Miguel Delibes, Paseo de Belén 7, 47011 Valladolid, Spain
}

(Received 20 December 2012; accepted 28 February 2013; published online 21 March 2013)

\begin{abstract}
In this article, the most relevant isomers of uranium tricarbide are studied through quantum chemical methods. It is found that the most stable isomer has a fan geometry in which the uranium atom is bonded to a quasilinear $\mathrm{C}_{3}$ unit. Both, a rhombic and a ring $\mathrm{CU}\left(\mathrm{C}_{2}\right)$ structures are found about $104-125 \mathrm{~kJ} / \mathrm{mol}$ higher in energy. Other possible isomers including linear geometries are located even higher. For each structure, we provide predictions for those molecular properties (vibrational frequencies, IR intensities, dipole moments) that could eventually help in their experimental detection. We also discuss the possible routes for the formation of the different $\mathrm{UC}_{3}$ isomers as well as the bonding situation by means of a topological analysis of the electron density. () 2013 American Institute of Physics. [http://dx.doi.org/10.1063/1.4795237]
\end{abstract}

\section{INTRODUCTION}

Uranium carbides are relevant in the nuclear industry due to their potential role as fuels for new generations of nuclear reactors. ${ }^{1}$ The relevance of this type of compounds has prompted a renewed interest on the properties of uranium carbides, particularly in the solid phase. However, due to the high temperatures reached in the operation of nuclear reactors, vaporization of these compounds is expected to be very important. Therefore, it is also interesting to have a detailed knowledge of the properties of uranium-carbon compounds in the gas phase. Nevertheless, little is known about the molecular structure of uranium-carbon compounds.

Experimental work on the gas-phase chemistry of uranium-carbon compounds dates to the 1960-1980 decades. ${ }^{2-6}$ Mass spectrometry studies allowed to obtain information about the stoichiometry of the uranium-carbon compounds formed in the gas phase as well as their relative abundances. More detailed information about their molecular structure has been obtained quite recently through spectroscopy studies. Wang et al. ${ }^{7,8}$ obtained uranium-carbon compounds through laser evaporation of uranium-carbon alloys followed by atom reaction in an argon matrix. Infrared absorption bands of $\mathrm{UC}$ and $\mathrm{UC}_{2}$ have been observed in these experiments. Theoretical studies have been also carried out for uranium dicarbide.$^{8-10}$ All of them agree in that the lowest lying species is a triangular (T-shape) isomer (quintet ground state). Despite this result, the species observed in the IR experiments was concluded to be a symmetric linear CUC isomer with a ${ }^{3} \Sigma_{\mathrm{u}}{ }^{+}$electronic state, which is predicted to lie about $238 \mathrm{~kJ} / \mathrm{mol}^{9}$ or $280 \mathrm{~kJ} / \mathrm{mol}^{10}$ higher in energy than the triangular isomer, according to the most reliable theoretical methods employed. Another possible isomer, a linear UCC species, is shown by theoretical calculations ${ }^{9}$ to be in fact a

\footnotetext{
a) Author to whom correspondence should be addressed. Electronic mail: alargo@qf.uva.es.
}

transition state for the degenerate rearrangement of the triangular species, since it has imaginary $\pi$ bending frequencies. Optimizations in $\mathrm{C}_{\mathrm{s}}$ symmetry led to the $\mathrm{C}_{2 \mathrm{v}}$-symmetric form. The fact that the observed $\mathrm{UC}_{2}$ species in the experiments is the linear CUC isomer, less stable than the triangular form, suggests that the conditions of the experiment might favor a chemistry dominated by $\mathrm{C}$ atom reactions, whereas the amount of $\mathrm{C}_{2}$ present in the matrix isolation experiments is too small to produce significant amounts of triangular $\mathrm{UC}_{2}$.

Other uranium-compounds have been found in the experiments. ${ }^{5,6,8}$ Therefore, it would be helpful to have a detailed knowledge of the molecular structure of new uraniumcarbon compounds. $\mathrm{UC}_{3}$ was observed in mass spectrometry experiments and some thermochemical properties were measured, ${ }^{5}$ although no structural data were obtained. Furthermore, $\mathrm{UC}_{3}$ is a potential species for observation in matrix isolation spectroscopic experiments, where other uraniumcarbon compounds have already been observed. ${ }^{7,8}$ Data on its molecular structure, stability, and spectroscopic properties should be very useful for the interpretation of such experiments. In the present work, we provide a detailed study of the molecular structure of uranium tricarbide, $\mathrm{UC}_{3}$. To the best of our knowledge, there is only a preliminary investigation by Wang et $a l .{ }^{8}$ at the Density Functional Theory (DFT) level for two isomers of $\mathrm{UC}_{3}$. Based on these calculations a band in the IR spectrum was assigned. ${ }^{8}$ As stated above, a detailed computational study of $\mathrm{UC}_{3}$ isomers is important to provide information to aid in the interpretation of the experiments, particularly for discriminating between the different $\mathrm{UC}_{\mathrm{x}}$ species. In addition, a second objective of the present work is to shed light on the growing patterns of $\mathrm{UC}_{\mathrm{n}}$ compounds. As we have mentioned earlier, the observation of $\mathrm{UC}_{2}$ suggests that the relative stabilities are not the only factors to be taken into account, and the experimental conditions also determines the predominant species that can be formed. At this end, the study of how uranium carbides grow in size incorporating more 
carbon atoms is of particular interest to predict the species that should be preferentially formed.

\section{COMPUTATIONAL METHODS}

We have employed similar quantum chemistry methods as in our previous work on uranium dicarbide. ${ }^{9}$ In first place molecular geometries have been optimized at the DFT level, employing the B3LYP exchange-correlation functional. ${ }^{11,12}$ Subsequently, geometries have been obtained at the CCSD (coupled-cluster single and double excitation model) level. The basis set employed consisted of a combination of the $6-311+\mathrm{G}(3 d f)$ basis set ${ }^{13}$ for carbon atom and the StuttgartDresden effective core potential (ECP60MWB) ${ }^{14,15}$ in conjunction with a $[8 s 7 p 6 d 4 f]$ basis set (referred to as "SDD" in GAUSSIAN 09) for uranium. Static relativistic effects are included in the Stuttgart-Dresden pseudopotential. Harmonic vibrational calculations have been performed in order to assess the nature of the stationary points on the potential energy surface as well as to estimate the zero-point energy (ZPE). The electronic energy has been refined by means of singlepoint calculations at the $\operatorname{CCSD}(\mathrm{T})$ level (CCSD augmented with a noniterative treatment of triple excitations). ${ }^{16}$ In the $\operatorname{CCSD}(\mathrm{T})$ calculations, we checked the T1 diagnostic. ${ }^{17}$ In most cases it was found below the 0.04 value, ${ }^{18}$ and only in one case a slightly higher value was found (around 0.05). These values do not suggest a strong multireference character of the wavefunctions. We have nevertheless carried out multiconfigurational calculations in order to check the adequacy of the single-reference theoretical methods. In particular, we performed CASSCF ${ }^{19,20}$ (complete active space multiconfiguration self-consistent field) optimizations followed by $\mathrm{MRCI}^{21,22}$ (multireference singles and doubles configuration interaction) single-point calculations. The active space was constructed including 10 electrons in 14 orbitals which for the $\mathrm{C}_{2 \mathrm{v}}$-symmetric structures comprise 5 orbitals from representation $a_{1}, 3$ from $b_{1}, 4$ from $b_{2}$, and 2 from $a_{2}$ (5342). For the linear $\mathrm{UC}_{3}$ structure, we found that a larger active space was required with additional $a_{1}$ and $b_{1}$ orbitals: (6442). For the MRCI calculations, all configurations with a coefficient larger than 0.02 in the CASSCF wavefunction have been taken into account. The sum of the squared norms of the selected reference configuration coefficients was between 0.977 and 0.989 . Eighteen valence electrons ( 4 from $\mathrm{C}$ and 6 from $\mathrm{U}$ ) have been correlated in the MRCI calculations. These multiconfigurational calculations were carried out in conjunction with the same basis sets described above for the single-reference methods. All the calculations were carried out with the GAUSSIAN $09^{23}$ and MOLPRO ${ }^{24}$ program packages.

The nature of the bonding in isomers of uranium tricarbide was characterized through the topological analysis of the electron charge density distribution, $\rho(\mathrm{r})$, in the framework of the atoms in molecules theory (AIM). ${ }^{25}$ Total electron densities were obtained at B3LYP level with the same basis sets described above. The bond and atomic properties were calculated using the AIMALL package. ${ }^{26}$ The accuracy of the integration over the atomic basin $(\Omega)$ was assessed by the magnitude of a function $L(\Omega)$, which in all cases is lower than $10^{-4}$ a.u.

\section{RESULTS AND DISCUSSION}

We have searched for possible isomers of the $\mathrm{UC}_{3}$ system. For each isomer different spin multiplicities were considered. We will only discuss in detail the lowest lying state for the most relevant isomers. The geometries of these species are given in Figure 1, whereas in Table I a summary of the main structural properties is provided. Their relative energies are collected in Table II. These structures can be rationalized in terms of their possible formation processes, which are depicted in Scheme 1.

In principle, one can devise three different schemes for $\mathrm{UC}_{3}$ formation: (i) from $\mathrm{UC}_{2}$, adding a carbon atom; (ii) from a uranium atom combined with $\mathrm{a}_{3}$ unit; (iii) combination of uranium monocarbide, $\mathrm{UC}$, with dicarbon, $\mathrm{C}_{2}$. In the first case, the formation of $\mathrm{UC}_{3}$ structures from both isomers of $\mathrm{UC}_{2}$, namely, linear and cyclic species, is shown in Scheme 1. It should be pointed out that in the experiments by Wang et al. ${ }^{7,8}$ the linear CUC isomer is apparently observed, but the $\mathrm{UC}_{2}$ cyclic isomer is considerably more stable. ${ }^{9,10}$ Therefore, the presence of cyclic $\mathrm{UC}_{2}$ cannot be ruled out. In fact the predicted dissociation energy of cyclic $\mathrm{UC}_{2}{ }^{9}$ agrees rather well with the value derived from previous mass spectrometry studies. ${ }^{5}$

It can be seen in Scheme 1 that if a carbon atom is attached to cyclic $\mathrm{UC}_{2}$ through a $\mathrm{U}-\mathrm{C}$ side, a fan structure is
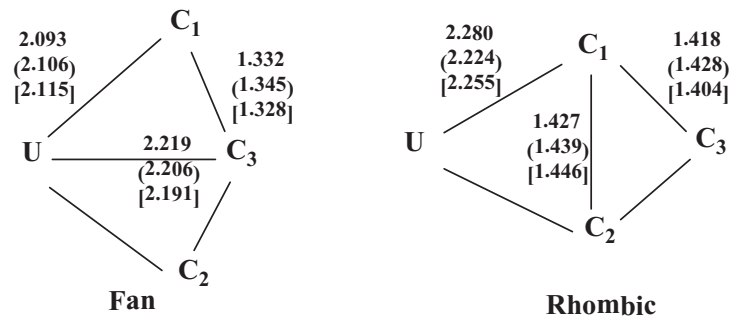

Rhombic
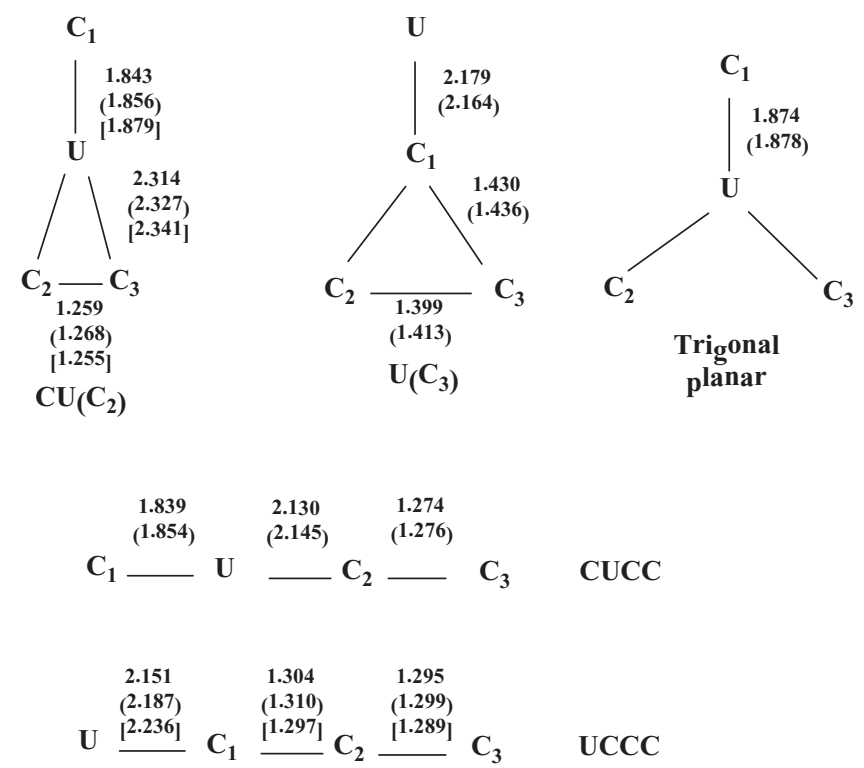

FIG. 1. Optimized geometries of the different $\mathrm{UC}_{3}$ species at the B3LYP, CCSD (in parentheses), and CASSCF (in squared brackets) levels of theory. Distances are given in $\AA$. 
TABLE I. Structural properties for the different $\mathrm{UC}_{3}$ species at selected levels of theory.

\begin{tabular}{|c|c|c|c|}
\hline Structure & Method & Vibrational frequencies $\left(\mathrm{cm}^{-1}\right)^{\mathrm{a}}$ & $\mu(\mathrm{D})$ \\
\hline \multirow[t]{2}{*}{$\operatorname{Fan}^{3} B_{1}$} & $\mathrm{~B} 3 \mathrm{LYP} / 6-311+\mathrm{G}(3 d f)+\mathrm{SDD}$ & $399\left(\mathrm{~b}_{2}, 8\right), 533\left(\mathrm{~b}_{1}, 65\right), 540\left(\mathrm{a}_{1}, 56\right), 790\left(\mathrm{a}_{1}, 15\right), 1275\left(\mathrm{a}_{1}, 6\right), 1529\left(\mathrm{~b}_{2}, 130\right)$ & 8.805 \\
\hline & $\mathrm{CCSD} / 6-311+\mathrm{G}(3 d f)+\mathrm{SDD}$ & $406\left(b_{2}, 0\right), 617\left(b_{1}, 10\right), 636\left(a_{1}, 144\right), 810\left(a_{1}, 4\right), 1265\left(a_{1}, 7\right), 1953\left(b_{2}, 644\right)$ & 9.489 \\
\hline \multirow[t]{2}{*}{ Rhombic ${ }^{5} \mathrm{~A}_{1}$} & $\mathrm{~B} 3 \mathrm{LYP} / 6-311+\mathrm{G}(3 d f)+\mathrm{SDD}$ & $227\left(b_{1}, 3\right), 385\left(b_{2}, 4\right), 424\left(a_{1}, 50\right), 964\left(b_{2}, 9\right), 1098\left(a_{1}, 38\right), 1430\left(a_{1}, 17\right)$ & 8.173 \\
\hline & $\mathrm{CCSD} / 6-311+\mathrm{G}(3 d f)+\mathrm{SDD}$ & $232\left(\mathrm{~b}_{1}, 1\right), 375\left(\mathrm{~b}_{2}, 7\right), 405\left(\mathrm{a}_{1}, 95\right), 985\left(\mathrm{~b}_{2}, 3\right), 1089\left(\mathrm{a}_{1}, 68\right), 1585\left(\mathrm{a}_{1}, 9\right)$ & 8.983 \\
\hline \multirow[t]{2}{*}{$\mathrm{CU}\left(\mathrm{C}_{2}\right){ }^{3} \mathrm{~B}_{1}$} & $\mathrm{~B} 3 \mathrm{LYP} / 6-311+\mathrm{G}(3 d f)+\mathrm{SDD}$ & $60\left(\mathrm{~b}_{2}, 72\right), 61\left(\mathrm{~b}_{1}, 72\right), 313\left(\mathrm{~b}_{2}, 16\right), 521\left(\mathrm{a}_{1}, 210\right), 910\left(\mathrm{a}_{1}, 76\right), 1844\left(\mathrm{a}_{1}, 15\right)$ & 1.002 \\
\hline & $\mathrm{CCSD} / 6-311+\mathrm{G}(3 d f)+\mathrm{SDD}$ & $98\left(\mathrm{~b}_{2}, 87\right), 85\left(\mathrm{~b}_{1}, 76\right), 339\left(\mathrm{~b}_{2}, 1\right), 529\left(\mathrm{a}_{1}, 263\right), 913\left(\mathrm{a}_{1}, 107\right), 1827\left(\mathrm{a}_{1}, 11\right)$ & 1.467 \\
\hline \multirow{2}{*}{ Trigonal planar ${ }^{3} \mathrm{~A}_{2}{ }^{\prime \prime}$} & $\mathrm{B} 3 \mathrm{LYP} / 6-311+\mathrm{G}(3 d f)+\mathrm{SDD}$ & $88\left(\mathrm{e}^{\prime}, 46\right), 160\left(\mathrm{a}_{2}^{\prime \prime}, 53\right), 720\left(\mathrm{e}^{\prime}, 61\right), 774\left(\mathrm{a}_{1}{ }^{\prime}, 0\right)$ & 0 \\
\hline & $\mathrm{CCSD} / 6-311+\mathrm{G}(3 d f)+\mathrm{SDD}$ & $168\left(\mathrm{e}^{\prime}, 4\right), 204\left(\mathrm{a}_{2}^{\prime \prime}, 45\right), 937\left(\mathrm{e}^{\prime}, 40\right), 760\left(\mathrm{a}_{1}{ }^{\prime}, 0\right)$ & 0 \\
\hline \multirow[t]{2}{*}{$\operatorname{CUCC}^{3} \Phi$} & $\mathrm{B} 3 \mathrm{LYP} / 6-311+\mathrm{G}(3 d f)+\mathrm{SDD}$ & $131 \mathrm{i}(\pi), 37(\pi), 483(\sigma), 921(\sigma), 1854(\sigma)$ & 3.324 \\
\hline & $\mathrm{CCSD} / 6-311+\mathrm{G}(3 d f)+\mathrm{SDD}$ & $142 \mathrm{i}(\pi), 58(\pi), 492(\sigma), 914(\sigma), 1876(\sigma)$ & 3.988 \\
\hline \multirow[t]{2}{*}{$\mathrm{UCCC}^{5} \Pi$} & $\mathrm{B} 3 \mathrm{LYP} / 6-311+\mathrm{G}(3 d f)+\mathrm{SDD}$ & $99 / 103(\pi, 1 / 1)^{\mathrm{b}}, 353(\sigma, 26), 391 / 404(\pi, 24 / 17)^{\mathrm{b}}, 1260(\sigma, 42), 1867(\sigma, 162)$ & 11.578 \\
\hline & $\mathrm{CCSD} / 6-311+\mathrm{G}(3 d f)+\mathrm{SDD}$ & $107(\pi, 0), 410(\sigma, 260), 428(\pi, 23), 1327(\sigma, 241), 1977(\sigma, 48)$ & 13.030 \\
\hline
\end{tabular}

${ }^{a}$ Mode symmetry and IR intensity $(\mathrm{km} / \mathrm{mol})$ in parentheses.

${ }^{b}$ Due to Renner-Teller effect, non-degenerate $\pi$ vibrational frequencies are obtained for the ${ }^{5} \Pi$ state.

formed, with the uranium atom bonded apparently to a quasilinear CCC unit. If the interaction takes place through the $\mathrm{C}-\mathrm{C}$ side of triangular $\mathrm{UC}_{2}$ a rhombic structure is obtained. Finally, bonding through the uranium atom results in a threemembered ring that will be referred to as $\mathrm{CU}\left(\mathrm{C}_{2}\right)$. There is another possibility, which corresponds to the interaction of a carbon atom with one of the carbon atoms in cyclic $\mathrm{UC}_{2}$. However, no stable structure is found in this way, since upon optimization it collapses into the fan isomer.

Starting now from linear CUC, the carbon atom can be attached to the uranium atom giving rise to a trigonal planar structure. A linear CUCC isomer is formed when the carbon atom interacts with one of the carbon atoms in CUC. Finally, the same ring $\mathrm{CU}\left(\mathrm{C}_{2}\right)$ structure commented before is obtained if carbon interacts through a $\mathrm{U}-\mathrm{C}$ bond.

When considering the formation of $\mathrm{UC}_{3}$ species from a uranium atom and $\mathrm{C}_{3}$, one should bear in mind that tricarbon has a linear ground state $\left({ }^{1} \Sigma_{\mathrm{g}}{ }^{+}\right){ }^{27}$ If the interaction takes place through a terminal carbon atom a linear UCCC structure is formed, whereas a side interaction leads again to the fan isomer. However, we have also considered the possibility of an interaction of a uranium atom with a hypothetical cyclic $\mathrm{C}_{3}$ unit. In such case, a side interaction produces the rhombic species, whereas a ring $\mathrm{U}\left(\mathrm{C}_{3}\right)$ structure is reached if the uranium atom interacts through an apex. However, the ring $\mathrm{U}\left(\mathrm{C}_{3}\right)$ species was shown to have two imaginary frequencies, and therefore will not be discussed in detail.

Considering the combination of uranium monocarbide, $\mathrm{UC}$, with dicarbon, $\mathrm{C}_{2}$, we arrive at some of the structures dis- cussed previously. If the interaction takes place with the $\mathrm{C}-\mathrm{C}$ bond (in a lateral way) three-membered rings are obtained, either $\mathrm{CU}\left(\mathrm{C}_{2}\right)$ or $\mathrm{U}\left(\mathrm{C}_{3}\right)$. On the other hand linear species (UCCC or CUCC) are obtained if the interaction takes place through one of the carbon atoms.

In addition, we have explored the $\mathrm{UC}_{3}$ potential surface, considering different multiplicities, searching for other possible stable structures. In particular, we have also searched for non-planar structures, but no stable species were obtained. Most structures shown in Figure 1 have triplet ground states. Only the rhombic isomer and the linear UCCC species have quintet ground states.

The fan isomer has a ${ }^{3} \mathrm{~B}_{1}\left[\cdots \mathrm{a}_{1}(5 f \phi) \mathrm{b}_{1}(5 f \sigma+\delta)\right]$ electronic state (the lowest-lying quintet, ${ }^{5} \mathrm{~A}_{1}$, lies about $63 \mathrm{~kJ} / \mathrm{mol}$ higher in energy at the $\operatorname{CCSD}(\mathrm{T})$ level). The $\mathrm{C}-\mathrm{C}$ bond distances are close to typical $\mathrm{C}-\mathrm{C}$ double bond distances. The $\angle \mathrm{CCC}$ angle is around $150^{\circ}$, showing a considerable deviation from linearity of the $\mathrm{C}_{3}$ unit. Based on the $\mathrm{U}-\mathrm{C}$ carbon distances, one is tempted to identify predominantly interactions of the uranium atom with the two equivalent carbon atoms $\mathrm{C}_{1}$ and $\mathrm{C}_{2}$. However, the distance between uranium and the central carbon atom cannot rule out a bonding interaction, since it is quite similar as the $\mathrm{U}-\mathrm{C}$ distance found in other cyclic structures. The fan species has a high dipole moment (8.8-9.4 D, depending on the level of theory employed). Both B3LYP and CCSD levels of theory predict that the most intense line in the IR spectrum should correspond to an asymmetric stretching of the $\mathrm{C}-\mathrm{C}-\mathrm{C}$ unit. However, both methods provide a rather different value for that

TABLE II. Relative energies $(\mathrm{kJ} / \mathrm{mol})$ at selected levels of theory for the most relevant $\mathrm{UC}_{3}$ species. $\mathrm{ZPE}$ corrections have been included.

\begin{tabular}{|c|c|c|c|c|c|c|}
\hline & Fan ${ }^{3} B_{1}$ & Rhombic ${ }^{5} \mathrm{~A}_{1}$ & $\mathrm{CU}\left(\mathrm{C}_{2}\right){ }^{3} \mathrm{~B}_{1}$ & Trigonal planar ${ }^{3} \mathrm{~A}_{2}{ }^{\prime \prime}$ & $\operatorname{CUCC}^{3} \Phi$ & $\mathrm{UCCC}^{5} \Pi$ \\
\hline $\mathrm{B} 3 \mathrm{LYP} / 6-311+\mathrm{G}(d)+\mathrm{SDD}$ & 0.0 & 47.57 & 141.17 & 638.02 & 202.46 & 118.83 \\
\hline $\mathrm{CCSD} / 6-311+\mathrm{G}(d)+\mathrm{SDD}$ & 0.0 & 71.59 & 123.14 & 656.01 & 194.97 & 142.72 \\
\hline $\operatorname{CCSD}(\mathrm{T}) / 6-311+\mathrm{G}(d)+\mathrm{SDD}$ & 0.0 & 107.70 & 124.31 & 600.86 & 199.53 & 181.71 \\
\hline \multirow[t]{2}{*}{ MRCI//CASSCF $(10,14)$} & 0.0 & 119.29 & 116.27 & & & \\
\hline & $(0.935)^{\mathrm{a}}$ & $(0.969)^{\mathrm{a}}$ & $(0.924)^{\mathrm{a}}$ & & & \\
\hline $\mathrm{MRCI} / / \mathrm{CASSCF}+\Delta \mathrm{SO}$ & 0.0 & 125.44 & 107.70 & & & \\
\hline
\end{tabular}

${ }^{a}$ Weight of the leading configuration in the CAS wave function. 


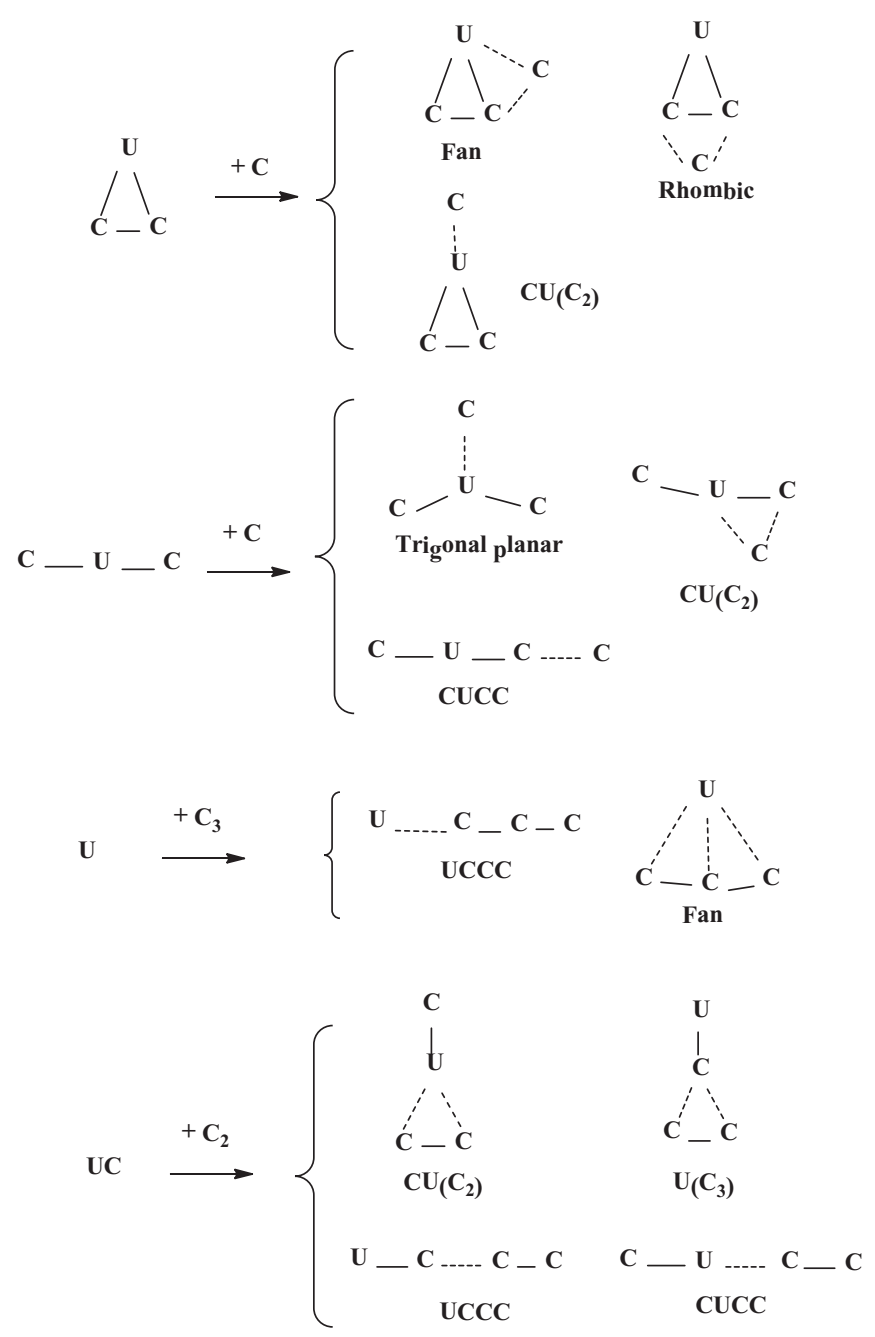

SCHEME 1. Schematic representation of the possible formation processes of $\mathrm{UC}_{3}$ species.

frequency $\left(1529 \mathrm{~cm}^{-1}\right.$ at the B3LYP level, $1953 \mathrm{~cm}^{-1}$ at the CCSD level).

Concerning the rhombic isomer in its ${ }^{5} \mathrm{~A}_{1}\left[\cdots \mathrm{a}_{2}(5 f \delta)\right.$ $\left.\mathrm{b}_{1}(5 f \pi) \mathrm{b}_{2}(5 f \phi) \mathrm{a}_{1}(5 f \sigma)\right]$ electronic ground state, the most interesting feature is the relatively short $\mathrm{C}_{1}-\mathrm{C}_{2}$ distance (very close to the peripheral $\mathrm{C}_{1}-\mathrm{C}_{3}$ and $\mathrm{C}_{2}-\mathrm{C}_{3}$ distances), which might suggest the presence of a true transannular carboncarbon bond, and therefore to classify this structure as a bicyclic species. Nevertheless, we will address these features later on with the help of an analysis of the electronic density. The rhombic species has also a high dipole moment, more than $8 \mathrm{D}$. The most intense line in the IR spectrum should correspond to the $\mathrm{U}-\mathrm{C}_{3}$ stretching (corresponding to $424 \mathrm{~cm}^{-1}$ at the B3LYP level and $405 \mathrm{~cm}^{-1}$ at CCSD), followed by a symmetric vibrational mode of the $\mathrm{C}_{3}$ unit (at 1098 or $1089 \mathrm{~cm}^{-1}$, depending of the level of theory employed).

In the $\mathrm{CU}\left(\mathrm{C}_{2}\right)$ isomer $\left[{ }^{3} \mathrm{~B}_{1} ; \cdots \mathrm{a}_{1}(5 f \sigma) \mathrm{b}_{1}(\phi)\right]$, we can clearly identify very different $\mathrm{U}-\mathrm{C}$ bond distances. The threemembered ring $\mathrm{UC}_{2}$ has very similar geometrical parameters as the ${ }^{5} \mathrm{~A}_{2}$ state of uranium dicarbide at the same levels of theory, ${ }^{9}$ whereas the $\mathrm{C}_{1}-\mathrm{U}$ bond distance approaches the bond distance found in linear CUC, namely, $1.834 \AA$ and $1.820 \AA$ at the B3LYP and CCSD levels, respectively. The predicted most intense line in the IR spectrum of this species corresponds to $521 \mathrm{~cm}^{-1}$ (B3LYP) or $529 \mathrm{~cm}^{-1}$ (CCSD). It is worth noting that the predicted frequencies for this species are in good agreement with the reported values by Wang et al. ${ }^{8}$ This species has two very low vibrational frequencies, below $100 \mathrm{~cm}^{-1}$, which could question its viability as a stable molecule, according to the criteria suggested by Hoffmann, Schleyer, and Schaefer. ${ }^{28}$ However, it should be taken into account that one of these frequencies $\left(b_{1}\right.$ symmetry) corresponds to out-of-plane vibration. These normal modes are usually characterized by rather flat potential curves, and are exceptions to the general criteria of Hoffmann et al. ${ }^{28}$ The second one ( $b_{2}$ symmetry) is associated with CUC bending, but it has a larger frequency at the CCSD level, approaching $100 \mathrm{~cm}^{-1}$. Although it corresponds to a shallow potential surface, it seems that at correlated level of theory it could be considered a stable isomer. This is also the case for the next isomer, the trigonal planar structure with $\mathrm{a}^{3} \mathrm{~A}_{2}$ " electronic state. At the B3LYP level, a low frequency $\left(88 \mathrm{~cm}^{-1}\right)$ is found. The CCSD level, on the other hand, predicts a somewhat higher value for this vibrational frequency, namely, $168 \mathrm{~cm}^{-1}$.

The lowest lying linear CUCC species corresponds to a ${ }^{3} \Phi$ electronic state. As can be seen in Table I, it has an imaginary frequency and therefore it is not a true minimum on the potential surface. Relaxing the symmetry constrains and performing a geometry optimization in $\mathrm{C}_{\mathrm{s}}$ symmetry it evolves toward the $\mathrm{CU}\left(\mathrm{C}_{2}\right)$ species. The lowest lying CUCC linear state with real frequencies corresponds to a ${ }^{3} \Sigma$ lying more than $335 \mathrm{~kJ} / \mathrm{mol}$ higher in energy than the ${ }^{3} \Phi$ state at the B3LYP level, and therefore it was not pursued any further. In Figure 1, it can be seen that CUCC has two rather different $\mathrm{U}-\mathrm{C}$ distances, being much shorter than that corresponding to the bond connecting uranium with the terminal carbon atom. Finally, a linear UCCC structure with a ${ }^{5} \Pi$ ground state was obtained. The geometrical parameters show two similar $\mathrm{C}-\mathrm{C}$ bond distances, which are slightly shorter than typical $\mathrm{C}=\mathrm{C}$ double bonds, and a relatively long $\mathrm{U}-\mathrm{C}$ distance, suggesting a weak interaction between uranium and carbon atoms. Based on the geometries of both linear isomers one is tempted to view CUCC as resulting from the interaction of $\mathrm{CU}+\mathrm{CC}$, whereas UCCC resembles a U+CCC interaction. An interesting point is that $\mathrm{CUCC}$ is shown to be in fact a transition state, whereas UCCC is a true minimum, since it has all its vibrational frequencies real. This is in contrast with the behavior observed for the $\mathrm{UC}_{2}$ system, because CUC is a true minimum, whereas UCC was shown to be in fact a transition state with imaginary $\pi$ vibrational frequencies. ${ }^{9}$ It is worth pointing out that the UCCC species has a large dipole moment, partly due to the arrangement of the atoms in this structure.

Relative energies at different levels of theory, namely, B3LYP, CCSD, CCSD(T), and MRCI, are given in Table II. Due to the large computational cost of the MRCI calculations we report values obtained for the three most stable structures according to the $\operatorname{CCSD}(\mathrm{T})$ predictions. All theoretical methods predict the fan isomer to be the most stable one, and therefore relative energies for the rest of species are referred to the fan isomer. In general, the different theoretical methods agree in the stability ordering of the different isomers. There is only a discrepancy concerning the ordering of $\mathrm{CU}\left(\mathrm{C}_{2}\right)$ and $\mathrm{UCCC}$, 
which is reversed when passing from B3LYP to CCSD. The $\operatorname{CCSD}(\mathrm{T})$ level, which should be more reliable, clearly places the linear isomer above the ring species. Let us also point out that the three most stable $\mathrm{UC}_{3}$ structures are mainly described by a single-reference whose weights are 0.935 (fan isomer), 0.969 (rhombic isomer), and $0.924\left[\mathrm{CU}\left(\mathrm{C}_{2}\right)\right.$ isomer].

The most interesting result is the prediction of the fan isomer as the global minimum for the $\mathrm{UC}_{3}$ system. According to the $\operatorname{CCSD}(\mathrm{T})$ results, the energy difference with the next lowest lying isomer, namely, the rhombic species, is large enough (more than $105 \mathrm{~kJ} / \mathrm{mol}$ ) to be confident in this prediction. The $\mathrm{CU}\left(\mathrm{C}_{2}\right)$ isomer is placed only nearly $92 \mathrm{~kJ} / \mathrm{mol}$ higher in energy than the rhombic species at the B3LYP level. Clearly, correlation effects favor triplet states over quintet states, as illustrated by the relative energies at the different levels of theory. At the most reliable level, $\operatorname{CCSD}(\mathrm{T})$, the energy difference between the rhombic and $\mathrm{CU}\left(\mathrm{C}_{2}\right)$ isomers is reduced to just $17 \mathrm{~kJ} / \mathrm{mol}$. It seems that there is a preference for cyclic isomers, since the two linear isomers are predicted to lie above the fan, rhombic, and $\mathrm{CU}\left(\mathrm{C}_{2}\right)$ species. The linear CUCC isomer with the uranium atom inserted into the carbon chain seems to be less stable than the UCCC species. Furthermore, the linear CUCC species has imaginary $\pi$ vibrational frequencies and therefore it is not in fact a stable structure. Only the linear UCCC species could be eventually considered as a possible candidate for experimental detection. The trigonal planar structure is not competitive, since it is found to lie more than $506 \mathrm{~kJ} / \mathrm{mol}$ above the fan isomer. Last row in Table II shows the MRCI relative energies of the three most stable isomers including the spin-orbit coupling. Inclusion of spin-orbit effects seems to increase the relative energy of the rhombic isomer while reducing that of the ring $\mathrm{CU}\left(\mathrm{C}_{2}\right)$ one. Thus, at the MRCI+SO level of theory the ring structure lies slightly below the rhombic isomer. Taking into account the accuracy of our calculations we may conclude that both isomers are virtually isoenergetic. In any case, the spin-orbit results do not change the general picture commented above: the fan isomer is clearly the most stable one.

It is not surprising that the fan and rhombic isomers are more stable than three-membered rings and linear species for uranium tricarbide. In a systematic study of small carbides for third-row main group elements, ${ }^{29}$ it was found that the more electronegative elements (As, $\mathrm{Se}, \mathrm{Br}$ ) favor linear or threemembered ring structures, whereas less electronegative elements $(\mathrm{K}, \mathrm{Ca}, \mathrm{Ga}, \mathrm{Ge})$ clearly prefer either fan or rhombic isomers. Uranium, with low ionization energy, behaves in a similar way as other electropositive elements such as $\mathrm{K}$ or Ca.

Taking into account the relative stabilities provided in Table II and the processes depicted in Scheme 1, we can discuss the formation of the different $\mathrm{UC}_{3}$ species. It seems that starting from the triangular $\mathrm{UC}_{2}$ isomer and adding a carbon atom the fan isomer would be preferentially formed. On the other hand, if we consider the formation from linear CUC the most stable species would be the $\mathrm{CU}\left(\mathrm{C}_{2}\right)$ isomer, since the linear CUCC is a transition state and the trigonal species lies much higher in energy. Considering the interaction of uranium atoms with linear CCC units, the preferred product should be the fan isomer, much more stable than the linear
$\mathrm{UCCC}$ species. Finally, if $\mathrm{UC}_{3}$ is produced from $\mathrm{UC}+\mathrm{C}_{2}$, the $\mathrm{CU}\left(\mathrm{C}_{2}\right)$ isomer should be the preferred product. Therefore, we might conclude that the fan and $\mathrm{CU}\left(\mathrm{C}_{2}\right)$ isomers should be preferentially obtained. Which of them is favored should depend on the formation process employed to produce $\mathrm{UC}_{3}$.

In order to characterize the nature of the bonding in the uranium $\mathrm{UC}_{3}$ species, we have applied the topological analysis of the electronic charge density. ${ }^{25}$ Within this formalism critical points in the one-electron density, $\rho(\mathrm{r})$, are identified. In our case, uranium tricarbide, only bond critical points [corresponding to a minimum value of $\rho(\mathrm{r})$ along the line connecting the nuclei and a maximum along the interatomic surfaces] and ring critical points $[\rho(\mathrm{r})$ being a minimum in two directions and a maximum in one direction] are relevant. A summary of the most relevant topological properties of the critical points is provided in Table III. In addition, the molecular graphs of electron density in conjunction with the contour maps of the Laplacian of the electron density are shown in Figure 2.

As it can be seen in the molecular graphs represented in Figure 2 the fan isomer $\left({ }^{3} \mathrm{~B}_{1}\right.$ electronic state) has two peripheral $\mathrm{U}-\mathrm{C}$ bond critical points $(\mathrm{BCP})$ and consequently a ring critical point (RCP), no $\mathrm{BCP}$ between uranium and the central carbon atom has been found, then it is clear that this species is a truly cyclic structure. Concerning the rhombic species two $\mathrm{BCP}$ between the uranium atom and $\mathrm{C}_{1}$ and $\mathrm{C}_{2}$ carbon atoms are found. In addition, a $\mathrm{C}_{1}-\mathrm{C}_{2}$ transannular bond critical point is observed. The presence of two RCPs as a consequence of the existence of a transannular carbon-carbon bond indicates that this species is in fact a bicyclic structure. This observation is also consistent with the $\mathrm{C}_{1}-\mathrm{C}_{2}$ distance (shorter than $1.5 \AA$ ).

In the $\mathrm{U}\left(\mathrm{C}_{3}\right)$ species, we have found a $\mathrm{U}-\mathrm{C}_{1}$ bond critical point, three $\mathrm{C}-\mathrm{C} B C P$ s and a ring critical point for the $\mathrm{C}_{3}$ unit. It can be concluded that the ring $\mathrm{U}\left(\mathrm{C}_{3}\right)$ species is a truly cyclic species. On the other hand, in the $\mathrm{CU}\left(\mathrm{C}_{2}\right)$ isomer no bond critical point between the uranium atom and the two equivalent carbon atoms $\mathrm{C}_{2}$ or $\mathrm{C}_{3}$ (and of course no ring critical point) can be found. This is a consistent with the large $\mathrm{U}-\mathrm{C}$ distance $(2.31 \AA$ ) observed in this case (see Figure 1). However, in addition to the $\mathrm{C}_{2}-\mathrm{C}_{3}$ and $\mathrm{U}-\mathrm{C}_{1}$ bond critical points, only a $\mathrm{BCP}$ between the uranium atom and the middle point of the $\mathrm{C}_{2}$ unit can be found (denoted U-CC). Therefore, this species is similar to a T-shape structure (see molecular graphs in Figure 2). This is not an unexpected behavior, since our previous results on uranium dicarbide also give rise to a T-shape structure. ${ }^{9}$ The predominance of $\pi$ interactions between $\mathrm{U}$ and the $\mathrm{C}_{2}$ moiety with respect to the weak $\sigma$ interactions, as illustrated by the molecular orbitals for uranium dicarbide, ${ }^{10}$ is in agreement with the finding of a single $\mathrm{U}-\left(\mathrm{C}_{2}\right)$ bond critical point.

In the case of both linear isomers, the presence of $\mathrm{U}-\mathrm{C}$ BCPs clearly shows the interaction between uranium and carbon atoms. Finally, in the trigonal planar ${ }^{3} \mathrm{~A}_{2}$ " species, three $\mathrm{U}-\mathrm{C}$ BCPs can be found.

The results of the AIM analysis provided in Table III give information about the nature of the interaction between the uranium and carbon atoms in uranium tricarbide species. In order to aid in this discussion, we show in Figure 2 the contour maps of the Laplacian distributions of the electronic charge 
TABLE III. Local topological properties (in a.u.) of the electronic charge density distribution calculated at the position of the bond critical points for the different $\mathrm{UC}_{3}$ species. ${ }^{\mathrm{a}}$

\begin{tabular}{lccrrr}
\hline \hline Species & Bond & $\rho(\mathrm{r})$ & $\nabla^{2} \rho(\mathrm{r})$ & $\mid V(\mathrm{r}) / / G(\mathrm{r})$ & $H(\mathrm{r})$ \\
\hline Fan ${ }^{3} \mathrm{~B}_{1}$ & $\mathrm{U}-\mathrm{C}_{1} ; \mathrm{U}-\mathrm{C}_{2}$ & 0.1598 & 0.1100 & 1.7685 & -0.0913 \\
& $\mathrm{C}_{1}-\mathrm{C}_{3} ; \mathrm{C}_{2}-\mathrm{C}_{3}$ & 0.3339 & -0.8797 & 3.2071 & -0.4021 \\
Rhombic ${ }^{5} \mathrm{~A}_{1}$ & $\mathrm{U}-\mathrm{C}_{1} ; \mathrm{U}-\mathrm{C}_{2}$ & 0.1036 & 0.1958 & 1.4392 & -0.0383 \\
& $\mathrm{C}_{1}-\mathrm{C}_{2}$ & 0.2698 & -0.3386 & 2.4981 & -0.2546 \\
& $\mathrm{C}_{1}-\mathrm{C}_{3} ; \mathrm{C}_{2}-\mathrm{C}_{3}$ & 0.2864 & -0.5337 & 2.8776 & -0.2854 \\
$\mathrm{CU}\left(\mathrm{C}_{2}\right){ }^{3} \mathrm{~B}_{1}$ & $\mathrm{U}-\mathrm{CC}$ & 0.1035 & 0.1722 & 1.4626 & -0.0371 \\
& $\mathrm{U}-\mathrm{C}_{1}$ & 0.2233 & 0.1088 & 1.8832 & -0.2056 \\
& $\mathrm{C}_{2}-\mathrm{C}_{3}$ & 0.4035 & -1.3114 & 3.4604 & -0.5523 \\
$\mathrm{U}\left(\mathrm{C}_{3}\right)^{5} \mathrm{~A}_{2}$ & $\mathrm{U}-\mathrm{C}_{1}$ & 0.1388 & 0.1040 & 1.7340 & -0.0717 \\
& $\mathrm{C}_{1}-\mathrm{C}_{2} ; \mathrm{C}_{1}-\mathrm{C}_{3}$ & 0.2667 & -0.3297 & 2.4818 & -0.2535 \\
& $\mathrm{C}_{2}-\mathrm{C}_{3}$ & 0.3097 & -0.7099 & 3.2031 & -0.3250 \\
Trigonal Planar ${ }^{3} \mathrm{~A}_{2}{ }^{\prime \prime}$ & $\mathrm{U}-\mathrm{C}_{1} ; \mathrm{U}-\mathrm{C}_{2} ; \mathrm{U}-\mathrm{C}_{3}$ & 0.2149 & 0.1370 & 1.8384 & -0.1777 \\
$\mathrm{CUCC}{ }^{3} \Phi$ & $\mathrm{U}^{-} \mathrm{C}_{1}$ & 0.2266 & 0.0910 & 1.9023 & -0.2101 \\
& $\mathrm{U}-\mathrm{C}_{2}$ & 0.1522 & 0.0641 & 1.8423 & -0.0856 \\
& $\mathrm{C}_{2}-\mathrm{C}_{3}$ & 0.3993 & -1.3938 & 3.8320 & -0.5387 \\
$\mathrm{UCCC}^{5} \Pi$ & $\mathrm{U}-\mathrm{C}_{1}$ & 0.1340 & 0.1701 & 1.6071 & -0.0657 \\
& $\mathrm{C}_{1}-\mathrm{C}_{2}$ & 0.3622 & -1.1853 & 3.8390 & -0.4575 \\
& $\mathrm{C}_{2}-\mathrm{C}_{3}$ & 0.3773 & -1.4224 & 4.4645 & -0.4999 \\
\hline \hline
\end{tabular}

${ }^{a}$ The electronic charge density $[\rho(\mathrm{r})]$, the Laplacian $\left[\nabla^{2} \rho(\mathrm{r})\right]$, the relationship between the local kinetic energy density $[G(\mathrm{r})]$ and the local potential energy density, $[V(\mathrm{r})]$, and the total energy density, $[H(\mathrm{r})]$.

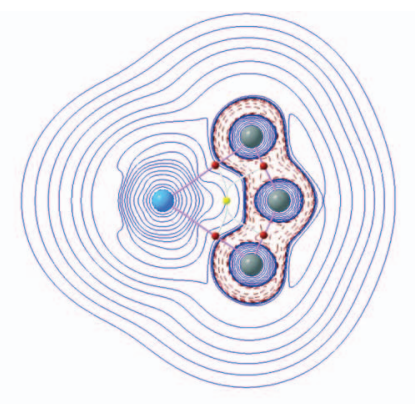

$\operatorname{Fan}^{3} \mathbf{B}_{1}$

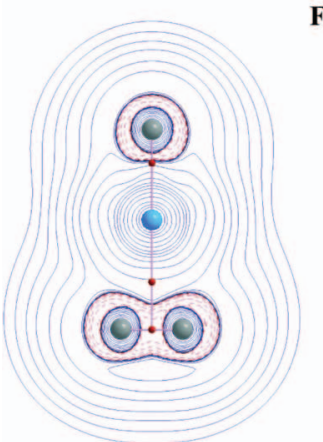

$\mathrm{CU}\left(\mathrm{C}_{2}\right){ }^{3} \mathrm{~B}_{1}$

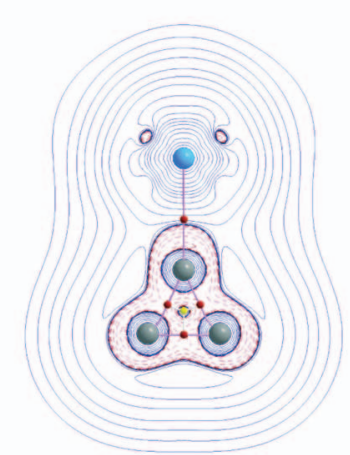

$\mathbf{U}\left(\mathrm{C}_{3}\right)^{5} \mathrm{~A}_{2}$

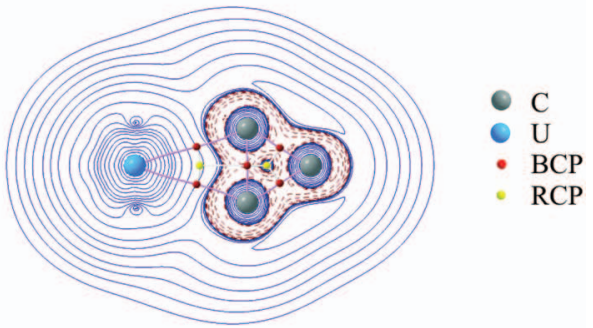

Rhombic ${ }^{5} \mathbf{A}_{1}$

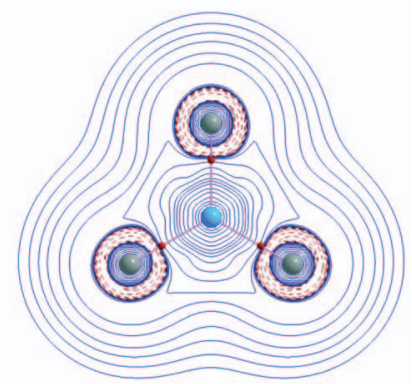

Trigonal Planar ${ }^{3} \mathbf{A}_{2}$

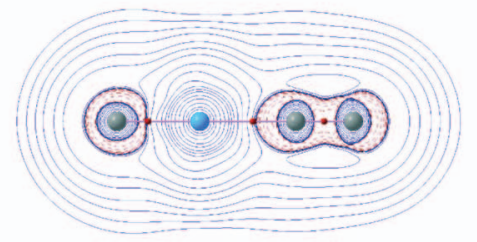

$\operatorname{CUCC}^{3} \Phi$

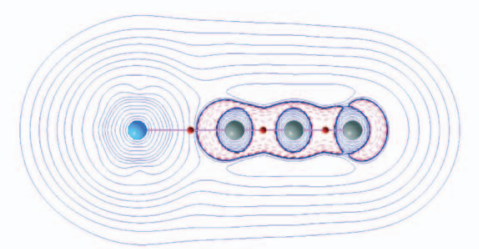

$\mathrm{UCCC}{ }^{5} \Pi$

FIG. 2. Contour maps of the Laplacian distribution of the electron density for the different $\mathrm{UC}_{3}$ species. Red dashed lines indicate regions of electronic charge concentration $\left(\nabla^{2} \rho(\mathrm{r})<0\right)$, and blue continuous lines denote regions of electronic charge depletion $\left(\nabla^{2} \rho(\mathrm{r})>0\right)$. Also molecular graphs of electron density are shown, small red spheres are bond critical points (BCPs), and small yellow spheres are ring critical points (RCPs). 
TABLE IV. Net atomic charge, $q(\Omega)$, obtained by integrating the charge density over the atomic basin (in a.u.).

\begin{tabular}{lccccccc}
\hline \hline$\Omega$ & Fan $^{3} \mathrm{~B}_{1}$ & Rhombic $^{5} \mathrm{~A}_{1}$ & $\mathrm{CU}\left(\mathrm{C}_{2}\right){ }^{3} \mathrm{~B}_{1}$ & $\mathrm{U}_{\left(C_{3}\right)}{ }^{5} \mathrm{~A}_{2}$ & Trigonal planar ${ }^{3} \mathrm{~A}_{2}{ }^{\prime \prime}$ & $\mathrm{CUCC}^{3} \Phi$ & $\mathrm{UCCC}{ }^{5} \Pi$ \\
\hline $\mathrm{U}$ & +1.60 & +1.17 & +1.91 & +1.12 & +1.56 & +1.92 & +1.29 \\
$\mathrm{C}_{1}$ & -0.59 & -0.56 & -0.78 & -0.78 & -0.52 & -0.80 & $-1.29^{\mathrm{a}}$ \\
$\mathrm{C}_{2}$ & -0.59 & -0.56 & -0.56 & -0.17 & -0.52 & -0.97 & \\
$\mathrm{C}_{3}$ & -0.41 & -0.05 & -0.56 & -0.17 & -0.52 & -0.14 & \\
\hline \hline
\end{tabular}

${ }^{a}$ Due to integration inconsistencies only the total charge of the $\mathrm{C}_{3}$ unit could be obtained.

densities. In addition, net atomic charges, $\mathrm{q}(\Omega)$, obtained by integrating the charge density over the atomic basin are given in Table IV.

Very briefly we may recall that two limiting types of interactions can be identified: shared interactions and closedshell interactions. ${ }^{30}$ Shared interactions, typical of covalent compounds, are characterized by large electron densities and negative values of the Laplacian, $\nabla^{2} \rho(\mathrm{r})$. On the other hand, closed-shell interactions correspond to relatively low values of $\rho(\mathrm{r})$ and positive values of its Laplacian, and are characteristic of ionic and van der Waals compounds. However, there is a whole spectrum of intermediate interactions lying between these two limiting cases. ${ }^{30}$ Another interesting property is the total energy density, $H(\mathrm{r})$, which is defined as the sum of the potential, $V(\mathrm{r})$, and kinetic, $G(\mathrm{r})$, energy densities at a critical point. The total energy density is useful to characterize the degree of covalency of a bond. If $H(\mathrm{r})$ is negative, the system is stabilized by the accumulation of electronic charge in the internuclear region, which is a typical characteristic of a covalent interaction..$^{31}$ On the other hand, when $H(\mathrm{r})$ is positive accumulation of charge density in the region between the nuclei leads to a destabilization of the system, which is the behavior observed for ionic interactions and van der Waals systems. ${ }^{30}$ Besides, the covalent character of an interaction can also be quantitatively analyzed by taking into account the $I V(\mathrm{r}) / / G(\mathrm{r})$ relationship. This relationship shows values greater than 2 for covalent interactions, smaller than 1 for non-covalent interactions and between 1 and 2 for partially covalent bonds. In other words, the $|V(\mathrm{r})| / G(\mathrm{r})$ ratio may be treated as a measure of the "covalence" of a bonding interaction.

As shown in Table III, all properties of $\mathrm{C}-\mathrm{C}$ bond critical points are typical of shared interactions: all have large values of electron density $(\rho(\mathrm{r})>0.25$ a.u.), negative values of its Laplacian $\nabla^{2} \rho(\mathrm{r}),|V(\mathrm{r})| / G(\mathrm{r})>2$ and the total energy density $H(\mathrm{r})$ is negative with large values.

Regarding $\mathrm{U}-\mathrm{C}$ bonds, the properties of the electron density at U-C BCPs in Table III are in line with our previously published data about the uranium dicarbides ${ }^{9}$ and, therefore, will be discussed in comparison with them.

In the fan ${ }^{3} \mathrm{~B}_{1}$ isomer the $\mathrm{U}-\mathrm{C}$ BCP shows a relatively low value of $\rho(\mathrm{r})$ and a positive value for $\nabla^{2} \rho(\mathrm{r})$. The $|V(\mathrm{r})| / G(\mathrm{r})$ and $H(\mathrm{r})$ values are indicative of a small degree of covalence in this bond. The trend of this bond is similar as the one that was observed for the $\mathrm{CCU}{ }^{5} \Sigma$ linear dicarbide, ${ }^{9}$ that is, closed-shell interactions with a partially covalent character.

In the $\mathrm{CU}\left(\mathrm{C}_{2}\right)$ isomer, the $\mathrm{UC}_{2}$ unit has very similar topological parameters as the ${ }^{5} \mathrm{~A}_{2}$ state of uranium dicarbide at the same level of theory, ${ }^{9}$ as would be expected. That is, a relatively low density value at the U-CC BCP, $\nabla^{2} \rho(\mathrm{r})>0$, and a small but negative value of $H(\mathrm{r})$ that suggests a slight degree of covalence. The rhombic structure also shows two $\mathrm{U}-\mathrm{C}$ bonds with similar characteristic. It can also be concluded that for both $\mathrm{CU}\left(\mathrm{C}_{2}\right)$ and rhombic species the U-C interactions can be classified as intermediate interactions, and that the degree of covalence is lower than for the other isomers. On the other hand, the $\mathrm{U}-\mathrm{C}_{1}$ bond on $\mathrm{CU}\left(\mathrm{C}_{2}\right)$ shows a moderate value of $\rho(\mathrm{r})$, a positive value for $\nabla^{2} \rho(\mathrm{r})$, $1<|V(\mathrm{r})| / G(\mathrm{r})<2$, and $H(\mathrm{r})$ shows a negative value. The $-H(\mathrm{r})$ values at the BCP in the $\mathrm{U}-\mathrm{C}_{1}$ bond is considerably greater that in the $\mathrm{U}-\mathrm{CC}$ bond which suggests a greater degree of covalency.

In the case of the trigonal center $\mathrm{U}$, the interactions with the three carbon atoms are equivalent. The $\mathrm{U}-\mathrm{C}$ bonds show properties similar to those found for the ground state of uranium monocarbide, UC. ${ }^{9}$ The covalent character in this species is similar as the $\mathrm{U}-\mathrm{C}_{1}$ bond in $\mathrm{CU}\left(\mathrm{C}_{2}\right)$.

Regarding the linear isomers, the $\mathrm{CUCC}^{3} \Phi$ species has two different $\mathrm{U}-\mathrm{C}$ bonds; both $\mathrm{U}-\mathrm{C}$ bonds show characteristic of closed-shell interactions with a partially covalent character. However, the $H(\mathrm{r})$ value at $\mathrm{U}-\mathrm{C}_{1} \mathrm{BCP}$ has significantly larger negative value than $\mathrm{U}-\mathrm{C}_{2}$, which suggests that the $\mathrm{U}-\mathrm{C}_{1}$ bond has a higher covalent character than $\mathrm{U}-\mathrm{C}_{2}$. These results are in accordance with the previous idea of viewing this isomer as resulting from the interaction of $\mathrm{CU}+\mathrm{CC}$. Similar properties were also found in UCCC structure, the covalent character in this species being smaller than $\mathrm{U}-\mathrm{C}_{2}$ bond in $\mathrm{CUCC}^{3} \Phi$ isomers. In addition, the results show that the covalent character in UCCC is smaller than U-C bond in linear dicarbide ${ }^{9}$ and monocarbide ${ }^{9}$ (following the order: UC $>$ UCC $>$ UCCC). This is indicative of a reduction of the covalent character in the $\mathrm{U}-\mathrm{C}$ bond in linear species as the length of the carbon chain increases.

In addition, as can we seen in Figure 2, all U-C BCPs lie in a zone of depletion of the electronic charge density, that is in the region of $\nabla^{2} \rho(\mathrm{r})>0$, in correspondence with a closedshell interaction. In contrast, the $\mathrm{C}-\mathrm{C} \mathrm{BCPs}$ lie in the region of charge concentration or shared interactions $\left(\nabla^{2} \rho(\mathrm{r})<0\right)$.

In summary, from the results collected in Table III and the contour maps represented in Figure 2 we can see that all the $\mathrm{U}-\mathrm{C}$ bonds in the different $\mathrm{UC}_{3}$ species are characterized by values of $\rho$ that are around $0.10-0.23$ a.u., whereas the Laplacian at the BCP are always positive. Furthermore, $H(\mathrm{r})$ is always slightly negative. Within AIM framework, such an interaction is usually considered as closed-shell interaction (ionic interactions) with some degree of covalence.

In addition, it is interesting to highlight that the two most stable isomers form ring structures that include the actinide and two-carbon atoms attached to the metal (i.e., the most 
stable fan species shows two $\mathrm{U}-\mathrm{C}$ interactions that lead to a 4-membered ring UCCC, while the rhombic species forms a three-membered ring UCC). Then, the relative stability of the different isomers could be also related to the ability of the uranium atom to form structures resulting in rings (three or four member in this case).

The net atomic charge, $q_{(\Omega)}$, on the uranium atom varies between +1.1 and $+1.9 e$ in agreement with the intermediate character of the bonding. The atomic charges are larger for the $\mathrm{CU}\left(\mathrm{C}_{2}\right)$ and $\mathrm{CUCC}$ isomers in agreement with their minor covalent character.

\section{CONCLUSIONS}

In this work, we have investigated by means of quantum chemical calculations the structure and bonding properties of uranium tricarbide $\left(\mathrm{UC}_{3}\right)$. A fan structure with the uranium atom bonded to a quasilinear $\mathrm{C}_{3}$ unit has been found to be the most stable isomer. Following in stability, we have found a rhombic species and a ring $\mathrm{CU}\left(\mathrm{C}_{2}\right)$ structure which appear to be virtually isoenergetic. They both lie well above the global minimum (104-125 kJ/mol). We have studied other possible isomers including linear arrangements CUCC and UCCC but they are located even higher. The analysis of the formation processes of the different $\mathrm{UC}_{3}$ isomers shows that formation of the fan isomer should be favored either if T-shape $\mathrm{UC}_{2}$ is present in the reaction medium or if $\mathrm{C}_{3}$ is formed by prior sequential carbon reactions. On the other hand, the ring $\mathrm{CU}\left(\mathrm{C}_{2}\right)$ isomer should be the most favored product if the reaction starts from linear CUC or uranium monocarbide UC. The only reaction that yields rhombic $\mathrm{UC}_{3}$ is (T-shape) $\mathrm{UC}_{2}$ $\left({ }^{5} \mathrm{~A}_{2}\right)+\mathrm{C}$ which, as stated above, should have the fan isomer as its primary product. Thus, we conclude that, as it was the case with uranium dicarbide, formation (and therefore observation) of the most stable isomer of $\mathrm{UC}_{3}$ seems to be strongly dependant on the reaction conditions.

The results obtained in the present work provide a detailed description of the stability and structure of the $\mathrm{UC}_{3}$ species. In addition, we have shown how the production of a particular $\mathrm{UC}_{3}$ isomer heavily depends on the experimental conditions. Therefore, this information should be useful to complement existing experimental work on $\mathrm{UC}_{\mathrm{x}}$ species ${ }^{5,7,8}$ as well as to guide possible new matrix isolation experiments on these compounds. The structural and stability data should be useful to discriminate between different $\mathrm{UC}_{\mathrm{X}}$ species.

Finally, the analysis of the bonding situation in these species has been carried out by means of a topological analysis of the electron density. It is shown that the fan isomer is a truly cyclic structure with two $\mathrm{U}-\mathrm{C}$ bonds. Besides, the rhombic isomer has been also shown to be a truly bicyclic species with a transannular $\mathrm{C}-\mathrm{C}$ bond. For the whole set of different isomers the $\mathrm{U}-\mathrm{C}$ interactions can be considered to be intermediate interactions with a small partial covalent character.

\section{ACKNOWLEDGMENTS}

This research has been supported by the Ministerio de Ciencia e Innovación of Spain (Grant No. CTQ201016864). M.F.Z. also acknowledges the Universidad Nacional del Nordeste and Consejo Nacional de Investigaciones Científicas y Técnicas of Argentina (CONICET).

${ }^{1}$ C. A. Utton, F. De Bruycker, K. Boboridis, R. Jardin, H. Noel, C. Gueneau, and D. Manara, J. Nucl. Mater. 385, 443 (2009).

${ }^{2}$ J. H. Norman and P. Winchell, J. Phys. Chem. 68, 3802 (1964).

${ }^{3}$ A. Pattoret, J. Drowart, and S. Smoes, Bull. Soc. Fr. Ceram. 77, 75 (1967).

${ }^{4}$ K. A. Gingerich, J. Chem. Phys. 50, 2255 (1969).

${ }^{5}$ S. K. Gupta and K. A. Gingerich, J. Chem. Phys. 71, 3072 (1979).

${ }^{6}$ B. P. Datta, V. L. Sant, V. A. Raman, C. S. Subbanna, and H. C. Jain, Int. J. Mass Spectrom. Ion Process. 91, 241 (1989).

${ }^{7}$ X. Wang, L. Andrews, P. A. Malmqvist, B. O. Roos, A. P. Gonçalves, C. C. L. Pereira, J. Marçalo, C. Godart, and B. Villeroy, J. Am. Chem. Soc. 132, 8484 (2010).

${ }^{8}$ X. Wang, L. Andrews, D. Ma, L. Gagliardi, A. P. Gonçalves, C. C. L. Pereira, J. Marçalo, C. Godart, and B. Villeroy, J. Chem. Phys. 134, 244313 (2011).

${ }^{9}$ M. F. Zalazar, V. M. Rayon, and A. Largo, J. Phys. Chem. A 116, 2972 (2012).

${ }^{10}$ P. Pogány, A. Kovács, Z. Varga, F. M. Bickelhaupt, and R. J. M. Konings, J. Phys. Chem. A 116, 747 (2012).

${ }^{11}$ A. D. Becke, J. Chem. Phys. 84, 4524 (1986).

${ }^{12}$ A. D. Becke, J. Chem. Phys. 88, 2547 (1988).

${ }^{13}$ R. Krishnan, J. S. Binkley, R. Seeger, and J. A. Pople, J. Chem. Phys. 72, 650 (1980).

${ }^{14}$ W. Kuechle, M. Dolg, H. Stoll, and H. Preuss, J. Chem. Phys. 100, 7535 (1994).

${ }^{15}$ B. O. X. Cao, M. Dolg, and H. Stoll, J. Chem. Phys. 118, 487 (2003).

${ }^{16}$ K. Raghavachari, G. W. Trucks, J. A. Pople, and M. Head-Gordon, Chem. Phys. Lett. 157, 479 (1989).

${ }^{17}$ T. J. Lee and P. R. Taylor, Int. J. Quantum Chem. 36(S23), 199 (1989).

${ }^{18}$ J. M. L. Martin, T. J. Lee, G. E. Scuseria, and P. R. Taylor, J. Chem. Phys. 97, 6549 (1992).

${ }^{19}$ H.-J. Werner and P. J. Knowles, J. Chem. Phys. 82, 5053 (1985).

${ }^{20}$ H.-J. Werner and P. J. Knowles, Chem. Phys. Lett. 115, 259 (1985).

${ }^{21}$ H.-J. Werner and P. J. Knowles, J. Chem. Phys. 89, 5803 (1988).

${ }^{22}$ H.-J. Werner and P. J. Knowles, Chem. Phys. Lett. 145, 514 (1988).

${ }^{23}$ M. J. Frisch, G. W. Trucks, H. B. Schlegel et al., GAUSSIAN 09, Gaussian, Inc., Wallingford, CT, 2010.

${ }^{24} \mathrm{H}$. J. Werner and P. J. Knowles, MOLPRO version 2002.1, a package of $a b$ initio programs, 2002, see http://www.molpro.net.

${ }^{25}$ R. W. F. Bader, Atoms in Molecules: A Quantum Theory (Clarendon Press, Oxford, 1990.

${ }^{26}$ T. A. Keith, AIMALL Version 11.12.19, TK Gristmill Software, Overland Park, KS, 2011.

${ }^{27}$ A. Van Orden and R. J. Saykally, Chem. Rev. 98, 2313 (1998).

${ }^{28}$ R. Hoffmann, P. v. R. Schleyer, and H. F. Schaefer, Angew. Chem., Int. Ed. 47, 7164 (2008).

${ }^{29}$ E. F. Villanueva, P. Redondo, V. M. Rayón, C. Barrientos, and A. Largo, Phys. Chem. Chem. Phys. 14, 14923 (2012).

${ }^{30}$ R. W. F. Bader, Chem. Rev. 91, 893 (1991).

${ }^{31}$ D. Cremer and E. Kraka, Angew. Chem., Int. Ed. Engl. 23, 627 (1984). 